Arq. Bras. Med. Vet. Zootec., v.62, n.3, p.639-644, 2010

\title{
Aspectos histológicos de fragmentos esplênicos autotransplantados em ratos
}

[Histopathologic aspects of splenic fragments autotransplanted in rats]

\author{
S.H. Freitas ${ }^{1}$, R.G.S. Dória ${ }^{1}$, F.S. Mendonça ${ }^{1}$, J. Evêncio Neto ${ }^{2}$, M.J. Simões ${ }^{3}$, L.M. Camargo ${ }^{1}$ \\ ${ }^{1}$ Faculdade de Medicina Veterinária - UNIC - Cuiabá, MT \\ ${ }^{2}$ Universidade Federal Rural de Pernambuco - Recife, PE \\ ${ }^{3}$ Escola Paulista de Medicina - UNIFESP - São Paulo, SP
}

\begin{abstract}
RESUMO
Estudou-se a viabilidade do autotransplante de tecido esplênico, um terço do baço, associado à esplenectomia parcial, e verificou-se a cinética evolutiva de sua regeneração, sob o aspecto macroscópico e histológico. Foram utilizados 28 ratos Wistar, adultos, machos, com média de peso de $300 \mathrm{~g}$, distribuídos em quatro grupos experimentais. Cada animal foi submetido à esplenectomia parcial, e um fragmento de baço foi transplantado para o omento maior, por períodos de 30, 60, 90 e 120 dias. Após cada período pré-estipulado, os tecidos esplênicos autotransplantados foram coletados e analisados histologicamente. Os resultados mostraram regeneração da cápsula esplênica, dos vasos sanguíneos e das polpas branca e vermelha. Aos 90 dias, a arquitetura microscópica apresentava-se semelhante à do baço normal.
\end{abstract}

Palavras-chave: rato, regeneração esplênica, baço

\begin{abstract}
The splenic tissue autograft viability (one third of the spleen) associated to parcial splenectomy was studied to verify the evolutive kinetic of its regeneration by macroscopic and histological aspects. Twenty-eight adult male Wistar rats, weighting 300g, were distributed in four experimental groups. Each animal was submitted to parcial splenectomy and one fragment of each spleen was autotransplanted to the greater omentum, for a period of 30, 60, 90, and 120 days. After each period, the autotransplanted splenic tissues were collected and histopathologically analyzed. The results showed regeneration of the splenic capsule, blood vessels, white pulp, and red pulp. After 90 days, the microscopic architecture was similar to the normal spleen.
\end{abstract}

Keywords: rat, splenic regeneration, spleen

\section{INTRODUÇÃO}

Durante algum tempo, considerou-se o baço como um órgão destituído de uma função importante, e sua remoção cirúrgica, após traumas, não era considerada danosa ao organismo (Banks, 1992; Carlton, 1998). A esplenectomia, muito difundida durante mais da metade do século XX, obteve grande aceitação, principalmente em relação a afecções hematológicas e ao trauma de baço, pela facilidade técnica e por coibir efetivamente a hemorragia. Sabe-se que o baço desempenha função relevante na imunidade e é importante para os elementos figurados do sangue, tanto da série vermelha como da branca. Está bem documentado que a esplenectomia pode resultar em sérias complicações hematolólogicas, hemostáticas e imunológicas (Tefferi et al., 2000; Akpek et al., 2001; Marques et al., 2002b; Simões et al., 2007).

O melhor conhecimento das consequências da esplenectomia resultou em mudanças na conduta cirúrgica em relação ao tecido esplênico, voltadas à sua conservação (Simões et al., 1990;

Recebido em 13 de fevereiro de 2009

Aceito em 30 de abril de 2010

e-mail: shfreitas@terra.com.br 
Martini et al., 1992; Souza et al., 2005). Para evitar as complicações da esplenectomia total, a esplenectomia segmentar é, com frequência, indicada, pois o remanescente esplênico possui capacidade de preservar a função imunológica de reservatório e de fagocitose (Torres et al., 2000; Marques et al., 2002c). Em casos em que a esplenectomia parcial não é possível de ser realizada, os autotransplantes de remanescentes esplênicos são indicados (Torres et al., 1993; Souza et al., 2005; Karagulle et al., 2007). Adicionalmente, em casos de trauma em que se opta pela esplenectomia parcial, embora a viabilidade do remanescente esplênico seja duvidosa, a realização de autoenxertos seria uma alternativa a mais para manutenção de tecido esplênico viável e preservação de suas funções, embora alguns estudos relatem que o organismo esplênico favoreça o desenvolvimento dos autoenxertos (Souza et al., 2005).

Embora o autotransplante esplênico tenha uma história de 20 anos, não há consenso sobre seus efeitos (Karagülle et al., 2007). A viabilidade do tecido esplênico implantado é ainda um assunto controverso no tocante a sua capacidade e qualidade de regeneração e está na dependência do montante de tecido e local escolhido para sua implantação (Souza et al., 2005). Alguns estudos têm demonstrado a capacidade do tecido esplênico autotransplantado de se regenerar, após ser desprovido de sua irrigação principal, tornando-se funcional (Rodrigues Jr. et al., 1987; Torres et al., 1994; Freitas et al., 2002). Geralmente, o fragmento autotransplantado de baço sofre necrose quase completa e depois se regenera para formar um baço normal. O suprimento sanguíneo do tecido esplênico é o fator mais importante e determinante para o sucesso do autotransplante. Diferentes locais e métodos de autotransplante têm sido estudados, mas parece que o suprimento sanguíneo, rico do omento maior, apresenta melhores resultados que os demais leitos receptores (Simões et al., 2007).

Experimentos com ratos mostram que há controvérsias em relação ao tempo de regeneração completa do baço (Simões et al., 2007), uma vez que não há consenso em relação aos métodos de avaliação do tecido implantado. Ainda assim, a histopatologia é a mais indicada para demonstrar a viabilidade do tecido (Karagülle et al., 2007).
Para avaliar a viabilidade do autotransplante de tecido esplênico associado à esplenectomia parcial, realizou-se um estudo experimental em ratos Wistar, em cujo omento maior foi implantado um terço do baço, com o objetivo de verificar a cinética evolutiva de sua regeneração sob os aspectos macroscópico e histológico.

\section{MATERIAL E MÉTODOS}

Foram utilizados 28 ratos Wistar, machos, adultos, com média de peso de $300 \mathrm{~g}$ (Aprovado pelo Comitê de Ética em Pesquisa Animal da Universidade de Cuiabá, MT). Após período de adaptação de sete dias, os animais foram confinados em gaiolas individuais e mantidos em ambiente com ração comercial e água ad libitum, temperatura de $21^{\circ} \mathrm{C}$ e iluminação artificial, com lâmpadas fluorescentes para estabelecer um fotoperíodo de 12 horas de claro e 12 horas de escuro.

Para realização do procedimento cirúrgico, os animais foram anestesiados com $50 \mathrm{mg} / \mathrm{kg}$ de cetamina (Vetanarcol, Koning do Brasil Ltda. Florianópolis, Brasil) e $25 \mathrm{mg} / \mathrm{kg}$ de xilazina(Virbaxil 2\%, Virbac do Brasil Ind. Com. Ltda. - São Paulo, Brasil), via intramuscular, na região posterior da coxa. Cada animal foi submetido à tricotomia da região abdominal e posicionado em decúbito dorsal. Após antissepsia, foi realizada celiotomia mediana préumbilical, por onde foi exposto o baço. Os vasos que irrigam e drenam o terço ventral do baço foram ligados duplamente, a $0,5 \mathrm{~cm}$ do hilo esplênico, seccionados transversalmente e separados do órgão. Na sequência, um fragmento de $1 \mathrm{~mm}$ do remanescente foi removido e processado histologicamente para controle. A cápsula esplênica parietal e visceral do remanescente (dois terços do baço) foi suturada com padrão de sutura contínua simples, utilizando fio de poliglactina 910 (Vicryl, Ethicon - São Paulo). O fragmento de tecido esplênico (um terço do baço) foi transferido para um leito receptor no omento maior, ao qual foi envolvido e fixado com o mesmo fio. A síntese da parede abdominal, do subcutâneo e da pele foi realizada com poliamida (Nylon, Brasmédica São Paulo). 
No pós-operatório, os animais receberam três aplicações subcutâneas de benzilpenicilina (Billi Farmacêutica Ltda. - São Paulo), na dose de $20.000 \mathrm{UI} / \mathrm{kg}$, com intervalo de 48 horas. As feridas foram tratadas com nitrofurazona (Furacin, Neo Química - São Paulo), e os pontos retirados ao sétimo dia.

Após a cirurgia, os animais foram distribuídos, ao acaso, em quatro grupos experimentais. Aos 30, 60, 90 e 120 dias de pós-operatório, os animais foram submetidos à eutanásia, grupos $\mathrm{E}_{1}, \mathrm{E}_{2}, \mathrm{E}_{3} \mathrm{e} \mathrm{E}_{4}$, respectivamente, utilizando-se o mesmo padrão de anestesia e cloreto de potássio (Aster Prod. Med. Ltda. - Sorocaba, Brasil) a $10 \%$. Por meio de incisão mediana pré-retroumbilical, realizou-se a exploração da cavidade abdominal, à procura do tecido esplênico implantado ao omento. Os tecidos esplênicos implantados e eventualmente regenerados foram analisados macroscopicamente quanto à reação com a área receptora, colhidos, seccionados em três partes iguais, sendo a intermediária fixada em formol (Vetec Química Fina - Duque de Caxias, Brasil) a 10\%, processada e corada pela hematoxilina e eosina (Bacha e Bacha, 2000). Os critérios de avaliação histológica envolveram a análise descritiva do corte histológico como um todo, em relação à constituição dos elementos histológicos (polpa vermelha ou seios venosos, vasos do parênquima esplênico, polpa branca, cápsula esplênica), os quais foram comparados com o baço normal.

\section{RESULTADOS}

Macroscopicamente, os autoenxertos de todos os animais permaneceram em seus leitos receptores, aderidos ao omento maior, com coloração semelhante à do baço normal, e apresentaram neovascularização adentrada à cápsula esplênica.

Microscopicamente, os autoenxertos apresentaram a superfície coberta por células mesoteliais e com uma fina cápsula de tecido fibroelástico. O parênquima esplênico nos ratos do grupo apresentava-se bastante irregular, contendo poucos nódulos de tecido linfóide, e a polpa vermelha mostrava-se bastante congesta, com inúmeros macrófagos, contendo no seu interior grânulos de hemossiderina (Fig. 1A e 2A). Nos do grupo $E_{2}$, a polpa branca apresentava pequenos nódulos linfáticos, contendo centros germinativos em atividade e bainhas linfoides periarteriais bem diferenciadas; a polpa vermelha já se apresentava semelhante ao tecido esplênico normal (Fig. 1B e 2B). Nos do grupos $E_{3}$ e $E_{4}$, os remanescentes esplênicos apresentavam-se semelhantes ao baço normal, contendo cápsula fibroelástica bem delimitada, com projeções para o seu interior formando trabéculas, com a polpa vermelha rica em vasos sanguíneos e a polpa branca formada por nódulos linfáticos bem delimitados com arteríolas centronodulares bastante típicas (Fig. 1C, 1D, 2C e 2D).

\section{DISCUSSÃO}

A ideia de que a retirada do baço era isenta de complicações passou a ser contestada quando se demonstrou que esse órgão era indispensável ao desempenho de vários mecanismos de defesa do organismo. Esse fato foi responsável pela conduta de se conservar o baço, sempre que possível, por meio da esplenectomia parcial e, mais recentemente, do autotransplante esplênico (Souza et al., 2005; Simões et al., 2007). Neste estudo ficou demonstrado que, quando a viabilidade do tecido esplênico for questionada, a associação da esplenectomia parcial ao autoenxerto de fragmento esplênico pode ser utilizada como uma forma de preservação de tecido esplênico viável.

Estudos prévios demonstram porcentagem de regeneração esplênica variando de 40 a $100 \%$ em seres humanos e animais que sofreram autoenxerto esplênico após esplenectomia total (Souza et al., 2005; Karagülle et al., 2007). Neste trabalho, verificaram-se $100 \%$ de sucesso na regeneração do autotransplante esplênico, mesmo quando associado à esplenectomia parcial. 


\section{Freitas et al.}
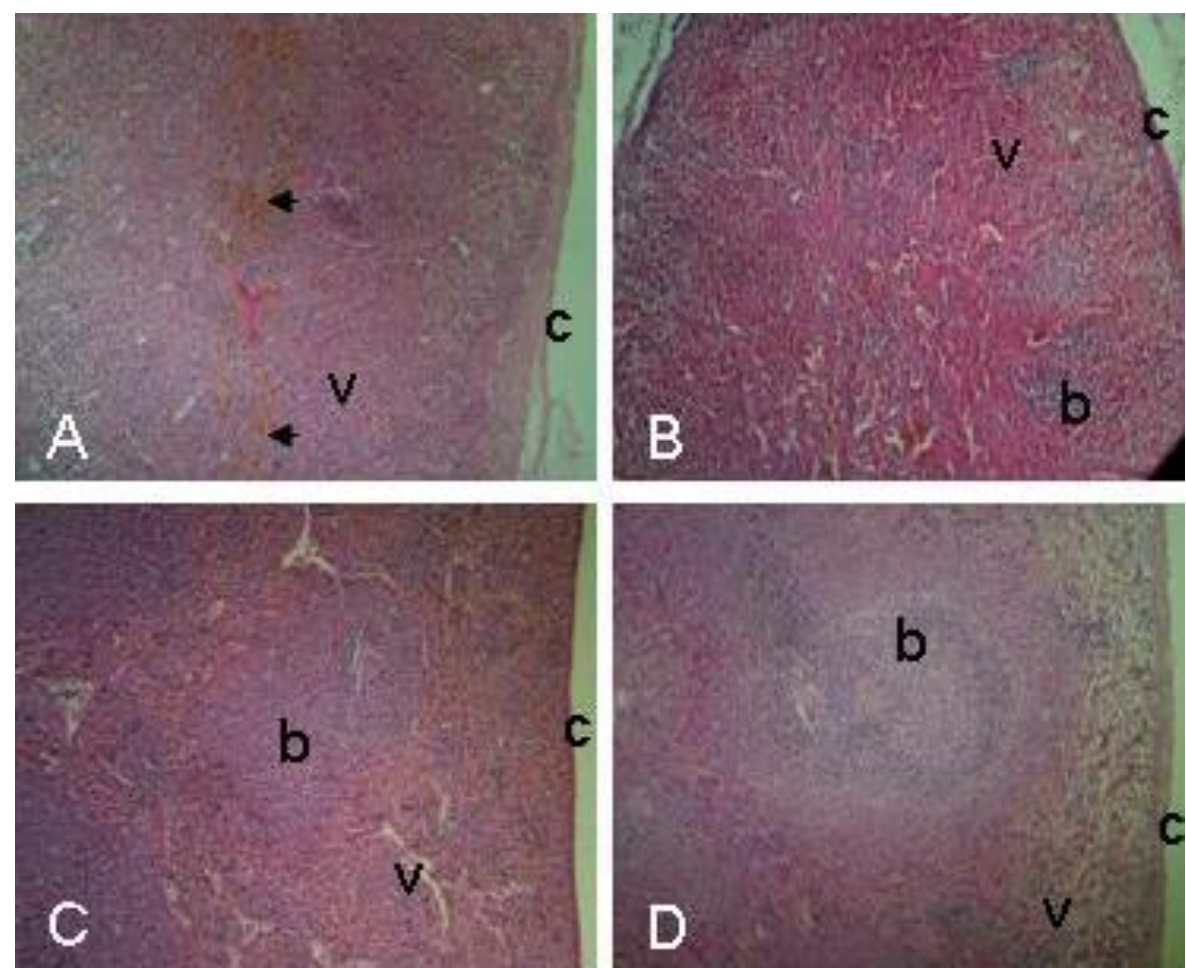

Figura 1. Fotomicrografia mostrando cortes histológicos do autoenxerto esplênico em ratos pertencentes aos vários grupos de estudo. A - 30 dias, B - 60 dias, C - 90 dias e D - 120 dias. Notar cápsula esplênica (c), polpa branca (b), polpa vermelha (v) e pigmentos de hemossiderina (H.E - 100X).
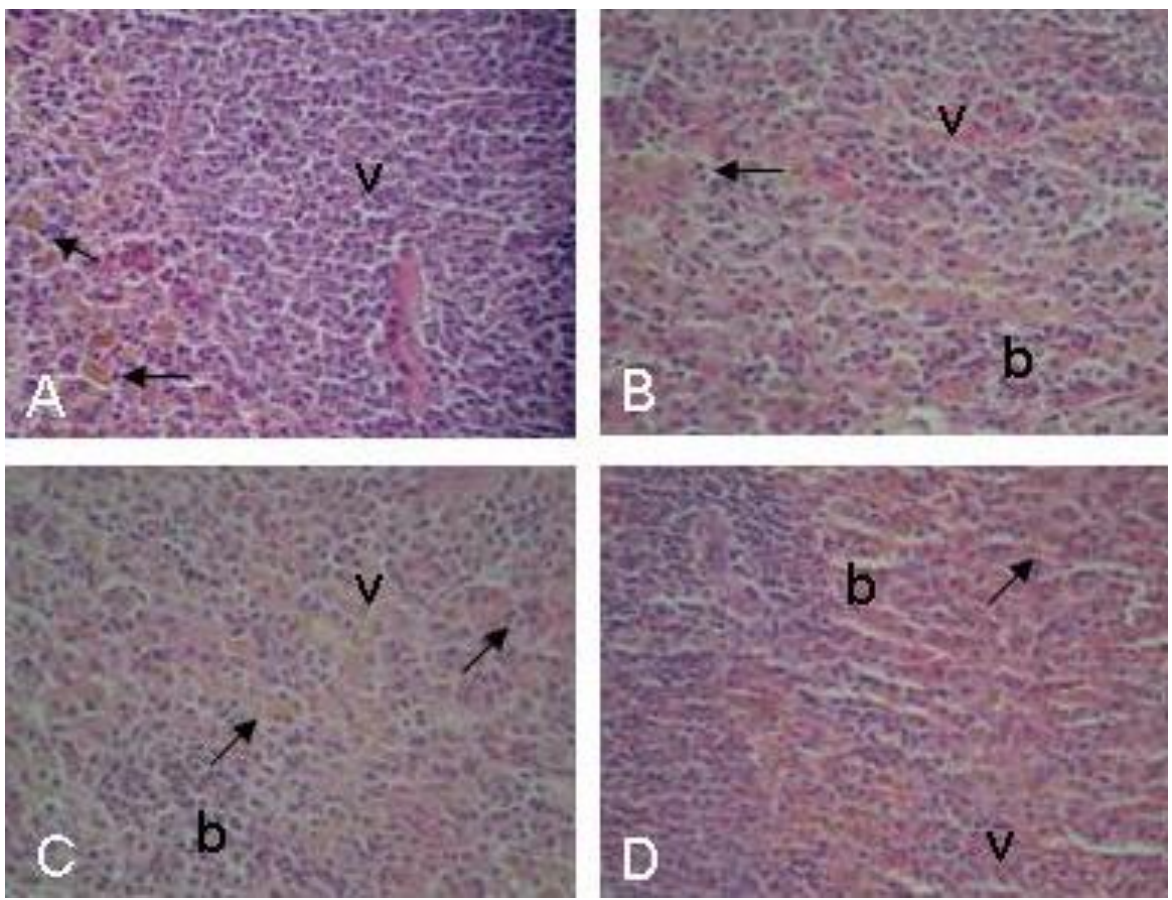

Figura 2. Fotomicrografia mostrando cortes histológicos do autoenxerto esplênico em ratos pertencentes aos vários grupos de estudo. A - 30 dias, B - 60 dias, C - 90 dias e D - 120 dias. Notar polpa branca (b), polpa vermelha (v) e pigmentos de hemossiderina (seta) (H.E - 400X). 
A técnica de autotransplante esplênico preconiza a realização de secções no sentido transversal do maior eixo do baço e recomenda a realização de quatro a seis implantes de dimensões milimétricas. Sugere, dessa forma, que os índices de sucesso da regeneração dos fragmentos de baço implantados têm relação direta com a superfície de contato e o sítio receptor (Souza et al., 2005). Por outro lado, este trabalho mostra a regeneração de $100 \%$ dos autoenxertos esplênicos com fragmento correspondendo a um terço do baço. Isto se deve ao fato de que, nos implantes múltiplos, o crescimento precoce de alguns deles pode prejudicar o desenvolvimento dos demais (Souza et al., 2005).

Estudos indicam, ainda, que a preservação do baço pode atuar como fator inibitório ao desenvolvimento do autotransplante, pois o organismo esplênico favorece o desenvolvimento dos autoenxertos (Souza et al., 2005), o que difere dos resultados desta pesquisa, que demonstrou $100 \%$ de regeneração dos fragmentos esplênicos autotransplantados em ratos com esplenectomia parcial.

O sucesso obtido nas regenerações dos autoenxertos esplênicos neste trabalho deveu-se, também, à utilização do omento maior como leito receptor, o qual favoreceu a regeneração do autotransplante, atribuída à manutenção do suprimento sanguíneo, com maior chance de estabelecimento de drenagem venosa com a circulação portal da cavidade abdominal (Souza et al., 2005; Karagülle et al., 2007). Neste estudo, foi possível observar a presença de neovascularização adentrando a cápsula esplênica desde 30 dias após o autoenxerto, semelhante ao resultado já obtido por Rodrigues et al. (1991), que relataram maior número de vasos neoformados nos tecidos regenerados no omento maior.

Ainda existem controvérsias em relação ao tempo que os fragmentos de baço autotransplantados requerem para se regenerar completamente, em ratos (Simões et al., 2007). Segundo Petroianu et al. (2000) e Silva et al. (2003), a regeneração do tecido esplênico, em ratos autotransplantados, é evidente e ocorre em curto espaço de tempo. Souza et al. (2005) relataram semelhança histológica e citológica entre os fragmentos de baço regenerados com o baço normal após 35 dias do autoenxerto, e Marques et al. (2002a; 2002c; 2004) verificaram que apenas após 112 dias o tecido esplênico regenerado se torna indistinguível de um baço normal. Da mesma forma, neste trabalho realizou-se um estudo evolutivo da regeneração dos fragmentos esplênicos autotransplantados e observou-se que houve regeneração da arquitetura esplênica já aos 30 dias e que, após 60 dias, os fragmentos esplênicos autotransplantados apresentavam características semelhantes à do baço normal (regeneração de polpa branca e vermelha). Aos 90 dias após o transplante, apresentavam arquitetura microscópica de um baço normal. Estes resultados confirmam os já citados por Church et al. (1981) e Rodrigues Jr. et al. (1987), que caracterizaram a capacidade de regeneração do autoenxerto esplênico no omento, com e sem remanescente, pelo restabelecimento da cápsula, polpa branca e polpa vermelha.

\section{CONCLUSÃO}

A regeneração do autoenxerto autólogo e heterotópico de fragmento esplênico único (um terço do baço) associado à esplenectomia parcial apresenta regeneração gradativa em relação ao tempo, atingindo, aos 90 dias, características histológicas de tecido esplênico normal.

\section{REFERÊNCIAS BIBLIOGRÁFICAS}

AKPEK, G.; McANENY, D.; WEINTRAUB, L. Risks and benefits of splenectomy in myelofibrosis with myeloid metaplasia. J. Surg. Oncol., v.77, p.42-48, 2001.

BACHA, W.J.; BACHA, L.M. Color atlas of veterinary histology. 2.ed. Philadelphia: Lippincott Willians \& Wilkins, 2000, 318p.

BANKS, W.J. Histologia veterinária aplicada. 2.ed. São Paulo: Manole, 1992. p.377-381.

CARLTON, W.W.; McGAVIN, M.D. Patologia veterinária especial. 2.ed. Porto Alegre: Artmed, 1998. p.305; p.349.

CHURCH, J.A.; MAHOUR, G.H.; LIPSEY, A.I. Antibody responses after splenectomy and splenic autoimplantation in rats. J. Surg. Res., v.31, p.343, 1981. 
FREITAS, S.H.; CAMARGO, L.M.; SÉBE, A.A. et al. Regeneração de tecido esplênico autotransplantado para o omento maior com remanescente tópico. In: CONGRESSO PAULISTA DE CLÍNICOS VETERINÁRIOS DE PEQUENOS ANIMAIS, 1., 2002, Águas de Lindóia, Anais... Águas de Lindóia: [s.n.] 2002. p. 63.

KARAGÜLLE， E.; HOFICOFIKUN， Z; KUTLU, A.K. et al. The effectiveness of splenic autotransplantation: an experimental study. Turk. J. Trauma Emerg. Surg., v.13, p.13-19, 2007.

MARQUES, R.G.; PETROIANU, A.; COELHO, J.M. et al. Regeneration of splenic autotransplants. Ann. Hematol., v.81, p.622-626, 2002a.

MARQUES, R.G.; PETROIANU, A.; OLIVEIRA, M.B.N. et al. Importância da preservação de tecido esplênico para a fagocitose bacteriana. Acta Cir. Bras., v.17, p.388-393, 2002b.

MARQUES, R.G.; PETROIANU, A.; OLIVEIRA, M.B. et al. Bacterial clearance after total splenectomy and splenic autotransplantation in rats. Appl. Radiat. Isot., v.57, p.767-771, 2002c.

MARQUES, R.G.; PETROIANU, A.; COELHO, J.M. et al. Morfologia e função fagocitária de implante esplênico autógeno regenerado em ratos. Acta Cir. Bras., v.19, p.642-648, 2004.

MARTINI, R.B.; GIMÉNEZ, O.A.; RIBICHINI, J.J. Delimitacion cromica para esplenectomia segmentária, hemostasia comparativa por eletrocoagulacion y laser de $\mathrm{CO}_{2}$. Rev. Argent. Cir., v.63, p.32-36, 1992.

PETROIANU, A.; VIDIGAL, F.M.; COSTA, V.C. et al. Splenic autotransplantation in Gaucher's disease. Dig. Surg., v.17, p.181-182, 2000.

RODRIGUES, A.Z.; NIGRO A.J.T.; PAIVA, E.R. et al. Estudo comparativo da viabilidade de fragmento de tecido esplênico implantado no omento maior ou na tela subcutânea em ratas. Acta Cir. Bras., v.6, p.64-67, 1991.
RODRIGUES Jr., A.J.; RODRIGUES, C.J.; YAMAMURO, E. et al. Desenvolvimento de autotransplantes intraperitoneais de baço com e sem remanescente esplênico tópico. (estudo experimental em ratos). Rev. Hosp. Clin. Fac. Med. São Paulo, v.42, p.209-212, 1987.

SILVA, R.G.; PETROIANU, A.; SILVA, M.G. et al. Influência das operações sobre o baço na distribuição da Escherichia coli no sistema mononuclear fagocitário. Rev. Col. Bras. Cir., v.30, p.65-71, 2003.

SIMOES, F.C.; MARQUES, R.G.; DIESTEL, C.F. et al. Perfil lipídico em ratos submetidos à esplenectomia total isolada ou combinada com autoimplante esplênico. Acta Cir. Bras., v.22, p.46-51, 2007.

SIMÕES, J.G.; POLÔNIO, P.; NETO, C.S. et al. Aspecto morfológico da reação tecidual da película celulósica inserida em esplenectomia parcial, hepatectomia parcial e no jejuno. Estudo experimental em cães. Acta Cir. Bras., v.3, p.8893, 1990.

SOUZA, J.C.L.; ATHIE, E.; MARIGO, C. et al. Estudo da regeneração esplênica autóloga e heterotópica em ratos. Acta Cir. Bras., v.20, p.253-257, 2005.

TEFFERI, A.; MESA, R.A.; NARONEY, D.M. et al. Splenectomy in myelofibrosis with myeloid metaplasia: a single-institution experience with 223 patients. Blood, v.95, p.2226-2233, 2000.

TORRES, O.J.M.; DIETZ, U.A.; LIMA, E.J.B. et al. Histological evaluation of the regeneration of splenic autotransplants. Acta Cir. Bras., v.9, p.81-87, 1994.

TORRES, O.J.M.; MALAFAIA, O.; SALAZAR, R.M. Esplenectomia e autotransplante esplênico. Rev. Bras. Med., v.50, p.1459-63, 1993.

TORRES, O.J.M.; MACEDO, E.L., PICCIANI, E.R.G. et al. Estudo histológico da regeneração esplênica de ratos submetidos à esplenectomia subtotal. Acta Cir. Bras., v.15, p.1-12, 2000. 